\title{
Losses Comparison Among Carrier-Based PWM Modulation Strategies in Three- Level Neutral-Point-Clamped Inverter
}

\author{
C. A. dos Santos and F. L. M. Antunes \\ Energy Processing and Control Group -GPEC \\ Electric Engineering Department - DEE \\ Federal University of Ceara - UFC \\ Caixa Postal 6001 - Campus do Pici, Fortaleza (Brazil) \\ Phone/Fax:+55 85 33669586/9574 e-mail: alisson@bsd.com.br, fantunes@ dee.ufc.br
}

\begin{abstract}
This paper investigates the power losses in semiconductors for a three-phase, three level neutral point clamped (3L-NPC) inverter. Analytical expressions for the switching and conductor losses are derived. Three different modulation strategies are analyzed: sinusoidal modulation (SPWM); sine modulation with injection of the third harmonic (THIPWM); carrier based space vector modulation (CBSVMPWM). Based on these strategies, the inverter losses are estimated through computational simulation under different operating conditions. The influence of these strategies on the losses is also analyzed.
\end{abstract}

\section{Key words}

Power Switch Losses, NPC Inverter, SVPWM, THIPWM, CB-SVPWM.

\section{Introduction}

Among the multilevel topologies, the most well know is the $3 \mathrm{~L}-\mathrm{NPC}$ inverter [1], which the power stage that can be seen in Figure 1. The main disadvantage of this structure is the imbalance in the distribution of loss in its semiconductor devices, leading to poor thermal distribution. Losses in power semiconductors depend on the PWM strategy adopted. This paper calculates and compares the losses in the inverter for three different PWM strategies: SPWM, THIPWM e CB-SVPWM. The operation limits of the converter, critical cases are determined and analyzed as show in Table I [2]. Operating under these limits the losses in the inverter have their maximum imbalance, limiting the switching frequency and the phase current of the converter.

Initially a mathematical approach for the inverter losses is developed, which allows to compare the losses in the NPC inverter for different modulation techniques. Then, the three techniques used will be presented and compared.
Table I. Critical operation cases for the 3L-NPC inverter for maximum loss imbalance among the power switches

\begin{tabular}{|c|c|c|c|}
\hline 3L-NPC & $\begin{array}{c}\text { Power } \\
\text { Factor }\end{array}$ & $\begin{array}{c}\text { Modulation } \\
\text { index }\end{array}$ & $\begin{array}{c}\text { More } \\
\text { losses }\end{array}$ \\
\hline Case 1 & 1 & max. & $\mathrm{S}_{11}, \mathrm{~S}_{14}$ \\
\hline Case 2 & 1 & min. & $\mathrm{Dc}_{11}, \mathrm{Dc}_{12}$ \\
\hline Case 3 & -1 & max. & $\mathrm{Df}_{11}, \mathrm{Df}_{14}$ \\
\hline Case 4 & -1 & min. & $\mathrm{S}_{12}, \mathrm{~S}_{12}$ \\
\hline
\end{tabular}

Losses in the inverter are estimated by computer simulations, taking into account different operating conditions.

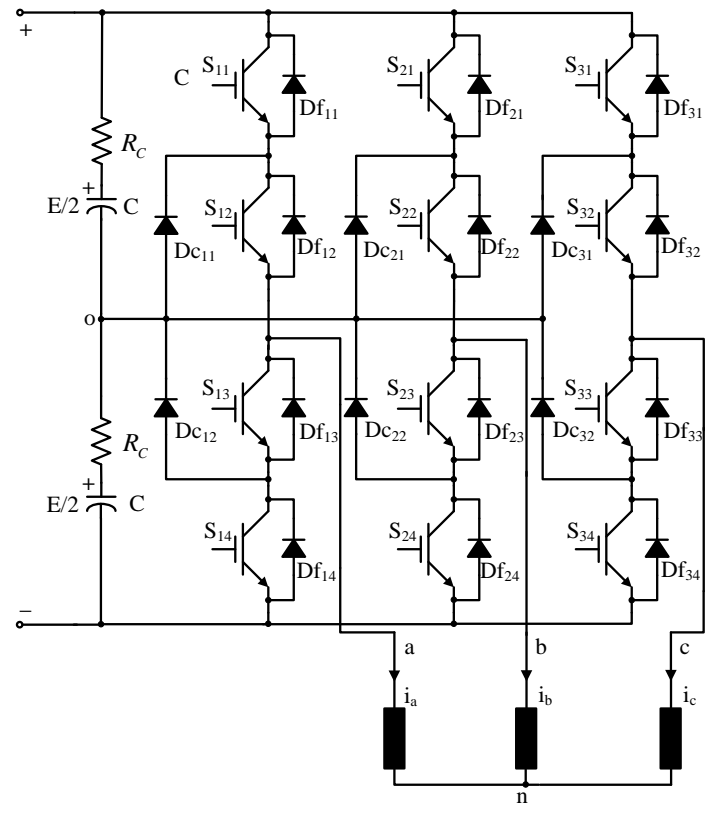

Fig. 1. Three-level NPC inverter. 


\section{The Three-level NPC Inverter}

The three-phase inverter consists of three arms, as illustrated in Figure 1. Each arm of the inverter is composed of four-way switches and two clamping diodes $\left(\mathrm{Dc}_{11}\right.$ and $\left.\mathrm{Dc}_{12}\right)$. Each switch consists of a IGBT $\left(\mathrm{S}_{11}, \mathrm{~S}_{12}\right.$, $\mathrm{S}_{13}$ and $\left.\mathrm{S}_{14}\right)$ and a anti-parallel diode $\left(\mathrm{Df}_{11}, \mathrm{Df}_{12}, \mathrm{Df}_{13}\right.$ and $\mathrm{Df}_{14}$ ). The first switch is composed by bidirectional IGBT $\mathrm{S}_{11}$ and the diode $\mathrm{Df}_{11}$. The IGBTs $\mathrm{S}_{11}$ and $\mathrm{S}_{14}$ are called external semiconductors; $S_{12}$ and $S_{13}$ internal. $S_{11}$ and $S_{13}$ are controlled in a complementary way, as well as $S_{12}$ and $\mathrm{S}_{14}$. Three states of control are possible: $\mathrm{P}, \mathrm{O}$ and $\mathrm{N}$ (Table II).

Table II. 3L-NPC inverter switching states

\begin{tabular}{|c|c|c|c|c|c|}
\hline \multirow{2}{*}{$\begin{array}{c}\text { Driving } \\
\text { State }\end{array}$} & \multirow{2}{*}{$\begin{array}{c}\text { Voltag } \\
\mathrm{e}\left(\mathrm{E}_{\mathrm{ao}}\right)\end{array}$} & \multicolumn{5}{|c|}{ Driven switches } \\
\cline { 3 - 6 } & $\mathrm{S}_{11}$ & $\mathrm{~S}_{12}$ & $\mathrm{~S}_{13}$ & $\mathrm{~S}_{14}$ \\
\hline $\mathrm{P}$ & $\mathrm{E} / 2$ & 1 & 1 & 0 & 0 \\
\hline $\mathrm{O}$ & 0 & 0 & 1 & 1 & 0 \\
\hline $\mathrm{N}$ & $-\mathrm{E} / 2$ & 0 & 0 & 1 & 1 \\
\hline
\end{tabular}

In order to analyze the switching states, the PWM modulation is initially considered. A sinusoidal reference voltage is compared with two triangular carriers which determine the voltage level desired as show in Figure 2. So:

- The converter is switched to $+\mathrm{E}_{\mathrm{dc}} / 2$, when the reference is larger than both carriers.

- The converter is switched to $-\mathrm{E}_{\mathrm{dc}} / 2$, when the reference is smaller than both carriers.

- O converter is switched to zero when the reference is larger than the lower carrier and smaller than the higher carrier.

For a positive output voltage, the inverter is switching between the states $\mathrm{P}$ and $\mathrm{O}-\mathrm{S}_{11}$ and $\mathrm{S}_{13}$ are active alternately. When $S_{11}$ stops conducting - state $\mathrm{P}, \mathrm{Dc}_{11}$ begins to conduct - state $\mathrm{O} . \mathrm{S}_{12}$ stays in conduction and $\mathrm{S}_{14}$ remains blocked. The determination which device is conducting, diode or IGBT, is determined by the direction of current.

Reciprocally, for a negative voltage, the inverter is switching between the states $\mathrm{N}$ and $\mathrm{O}-\mathrm{S}_{13}$ and $\mathrm{S}_{14}$ are activated alternately. A summary of the operation of the converter is shown in Table III [3].

Table III. Operating states of the NPC converter

\begin{tabular}{|c|c|c|c|}
\hline Current & $\begin{array}{c}\text { Devices } \\
\text { conducting }\end{array}$ & $\begin{array}{c}\text { Conduction } \\
\text { intervals }\end{array}$ & $\begin{array}{c}\text { Output } \\
\text { Voltage }\end{array}$ \\
\hline \multirow{3}{*}{$I_{o}>0$} & $\mathrm{~S}_{11}, \mathrm{~S}_{12}$ & {$[\theta, \pi]$} & $\mathrm{E} / 2$ \\
\cline { 2 - 4 } & $\mathrm{Dc}_{11}, \mathrm{~S}_{12}$ & {$[\theta, \pi] \mathrm{e}[\pi, \pi+\theta]$} & 0 \\
\cline { 2 - 4 } & $\mathrm{Df}_{14}, \mathrm{Df}_{13}$ & {$[\pi, \pi+\theta]$} & $-\mathrm{E} / 2$ \\
\hline \multirow{3}{*}{$I_{o}<0$} & $\mathrm{~S}_{13}, \mathrm{~S}_{14}$ & {$[\pi+\theta, 2 \pi]$} & $-\mathrm{E} / 2$ \\
\cline { 2 - 4 } & $\mathrm{S}_{13}, \mathrm{Dc}_{12}$ & {$[\pi+\theta, 2 \pi] \mathrm{e}[0, \theta]$} & 0 \\
\cline { 2 - 4 } & $\mathrm{Df}_{12}, \mathrm{Df}_{11}$ & {$[0, \pi]$} & $\mathrm{E} / 2$ \\
\hline
\end{tabular}

\section{Modulation Techniques}

\section{A. Sinusoidal Modulation (SPWM)}

In a sinusoidal PWM modulation a sinusoidal reference is compared with two triangular carriers, as illustrated in Figure 2.

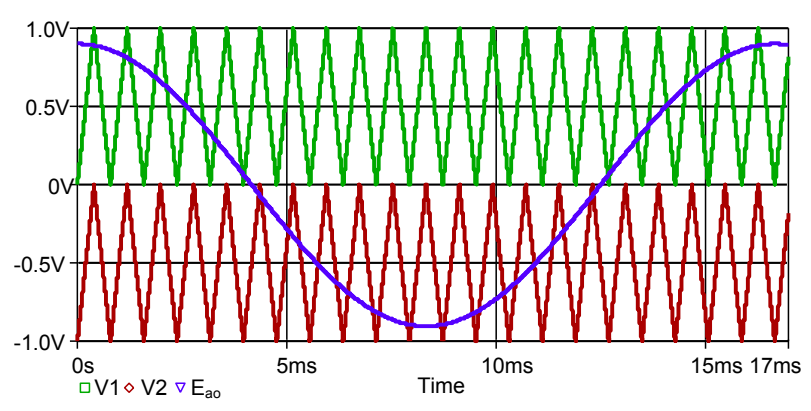

Fig. 2. Sinusoidal PWM modulation (SPWM)

The function of the sinusoidal modulation is shown in equation (1)

$$
f_{S P W M}(t)=M \sin (t)
$$

The pulse command devices on the 3L-NPC inverter occur in different periods and its role in modulation differs for each period. A summary of the conduction intervals for each semiconductor, and related functions of modulation is given in Table IV. With this information is possible to determine the average and RMS values of currents for each switch.

\section{B. SVPWM with third harmonic injection (THIPWM)}

The maximum modulation index can increase the drive without entering in the region of over-modulation, when added a zero sequence component in the sinusoidal reference [4]. This signal does not influence the fundamental component of line voltage at the converter output. The equation (2) comes from (1) with the inclusion of the third harmonic.

$$
f_{\text {THIPWM }}(t)=\frac{2}{\sqrt{3}} M\left(\sin (t)+\frac{1}{6} \sin (3 t)\right)
$$

The new reference signal in which is included a 3rd harmonic waveform is seen in Figure 3. 


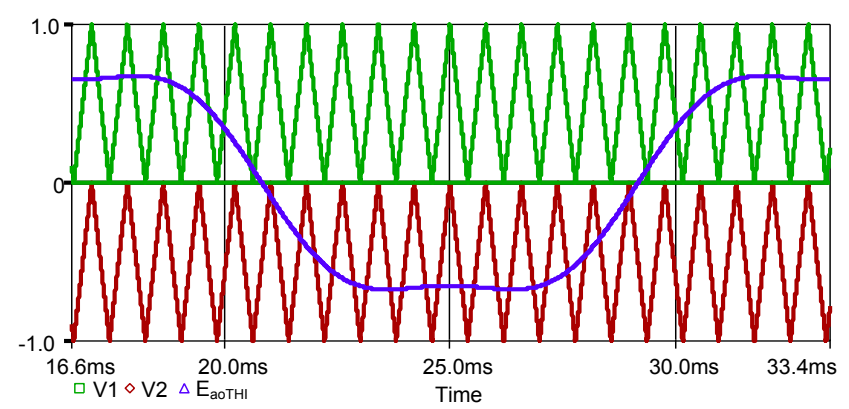

Fig. 3. SPWM with third harmonic injection (THIPWM)

The states defined in Table III are also valid for this modulation technique.

\section{Carrier-based space vector modulation (CB-SVM)}

The space vector modulation has been widespread and diverse works exploring their relationship to PWM-based carrier has been published [5] - [9]. SVM can be implemented by a sinusoidal reference with the addition of a zero-sequence duty cycle. The algorithm proposed in [9] for the case of NPC inverter is considered.

For all references $\{\mathrm{Ea}, \mathrm{Eb}, \mathrm{Ec}\}$, with $\mathrm{x}=\mathrm{a}, \mathrm{b}, \mathrm{c}$ :

if $\left(-0.867<E_{x}<0.867\right)$

$E_{z}=\left(1-\delta_{\max }+\delta_{\min }\right) \cdot k-\delta_{\min }$

else if $\left(E_{x}>0.867\right)$

$E_{z}=\left(1-2 \delta_{\text {min }}-\delta_{\text {max }}\right) \cdot k-1+\delta_{\text {min }}+\delta_{\text {max }}$

else

$E_{z}=\left(-2+\delta_{\min }+2 \delta_{\max }\right) \cdot k+1-\delta_{\max }$

The new reference is given by:

$$
f_{C B-S V M P W M}(t)=\frac{2}{\sqrt{3}} E_{x}(t)+E_{z}(t)
$$

Figure 4 illustrates the CB-SVPWM modulation.

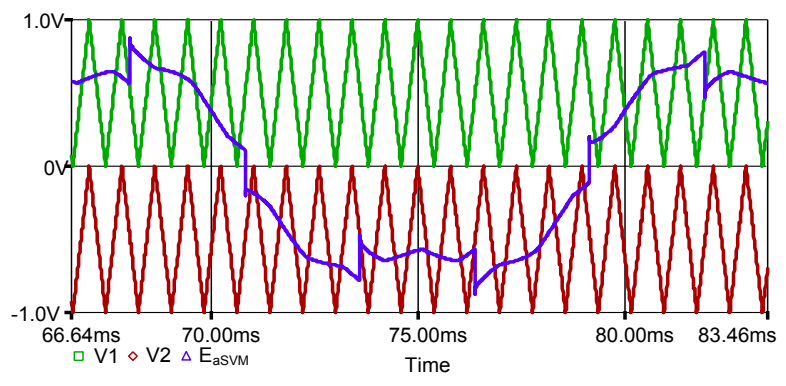

Fig. 4. Carrier-based space vector modulation (CB-SVM).

\section{Losses Modeling}

The losses in a semiconductor device comprising the conductor losses, losses due to conduction block in the output (usually neglected), losses by into in conduction and switching off losses. The switching losses at the turn on are affected by the reverse recovery of diodes. The device technology and the modulation strategy adopted influence these losses. The method used to estimate losses in this paper is an extension of the methods discussed in [10] e [11].

The total losses are the summation of the commutation plus the conduction losses

$$
P_{X}=P_{c o n X}+P_{s w X}
$$

\section{A. Static characteristics of the devices}

The characteristic curve of voltage/current of an IGBT can be approximated by:

$$
V_{C E}=\frac{V_{C E N}-V_{C E 0}}{I_{C N}} I_{C}+V_{C E 0}
$$

In the same manner the static behavior of a fast reverse diode is given by:

$$
V_{F}=\frac{V_{F N}-V_{F 0}}{I_{C N}} I_{C}+V_{F 0}
$$

Then,

$$
r_{d S}=\frac{V_{C E N}-V_{C E 0}}{I_{C N}} \text { e } r_{d D}=\frac{V_{F N}-V_{F 0}}{I_{C N}}
$$

Those parameters can be obtained directly from IGBT manufacturer datasheet.

The load current is supposed to be sinusoidal (8).

$$
i_{C}=I_{C M} \sin (t-\theta)
$$

\section{B. Conduction losses}

The switches conduction losses $P_{\text {cons }}$ and diodes conduction losses $P_{\text {conD }}$ are mathematically represented by (9) e (10).

$$
\begin{gathered}
P_{c o n s}=I_{a v g} V_{C E 0}+I_{r m s}^{2} r_{d S} \\
P_{c o n D}=I_{a v g} V_{F 0}+I_{r m s}^{2} r_{d D}
\end{gathered}
$$

Where $I_{a v g}$ and $I_{r m s}$ are average and RMS values of the current through the device. $V_{C E 0}$ and $V_{F 0}$ are threshold voltages of the IGBT and diode, respectively. $r_{d S}$ and $r_{d D}$ are the device resistences.

The average value of the current $I_{a v g}$ is given by: 
Table IV. Modulation functions and conduction intervals

\begin{tabular}{|c|c|c|c|c|c|c|c|}
\hline 3L-NPC & $\mathrm{S}_{11}$ & $\mathrm{Df}_{11}$ & \multicolumn{2}{|c|}{$\mathrm{S}_{12}$} & $\mathrm{Df}_{12}$ & \multicolumn{2}{|c|}{$\mathrm{Dc}_{11}$} \\
\hline Interval & {$[\theta, \pi]$} & {$[0, \theta]$} & {$[\theta, \pi]$} & {$[\pi, \pi+\theta]$} & {$[0, \theta]$} & {$[\theta, \pi]$} & {$[\pi, \pi+\theta]$} \\
\hline$f(t)$ & $M \sin (t)$ & $M \sin (t)$ & 1 & $1+M \sin (t)$ & $M \sin (t)$ & $1-M \sin (t)$ & $1+M \sin (t)$ \\
\hline
\end{tabular}

$$
I_{\text {avg }}=\frac{1}{2 \pi} \int_{\alpha_{1}}^{\alpha_{2}} I_{C M} \sin (t-\theta) \cdot f_{X}(t) d t
$$

The rms value is given by:

$$
I_{r m s}=\sqrt{\frac{1}{2 \pi} \int_{\alpha_{1}}^{\alpha_{2}} I_{C M} \sin (t-\theta)^{2} \cdot f_{X}(t) d t}
$$

Where $f_{X}(t)$ is the specified modulation function. It should be considered the current though the device for interval $\left[\alpha_{1}, \alpha_{2}\right]$.

As an example, the procedure to calculate the losses on $\mathrm{S}_{11}$ with THIPWM is presented. From Table III and Table IV it is seen that $S_{11}$ conducts during the interval $[\theta, \pi]$. The modulation function is expressed by (13).

$$
f_{\text {THIPWMS } 11}(t)=\frac{2}{\sqrt{3}} M\left(\sin (t)+\frac{1}{6} \sin (3 t)\right)
$$

The average and rms values of the current through $S_{11}$ can be represented by (14) and (15).

$$
\begin{aligned}
I_{\text {avg } S 11} & =\frac{1}{2 \pi} \int_{\theta}^{\pi} I_{C M} \sin (t-\theta) \frac{2}{\sqrt{3}} M \sin (t)+\frac{1}{6} \sin (3 t) d t \\
I_{r m s} & =\sqrt{\frac{1}{2 \pi} \int_{0}^{\pi} I_{C M} \sin (t-\theta){ }^{2} \frac{2}{\sqrt{3}}^{M} \sin (t)+\frac{1}{6} \sin (3 t) d t}
\end{aligned}
$$

For other devices the calculation is done in a similar way by taking the appropriate modulation function in the conduction interval of the required device.

\section{Commutation losses}

The commutation losses for the 3L-NPC inverter occur at the intervals shown in Table V. The commutation losses on diodes $\mathrm{D}_{\mathrm{f} 12}$ e $\mathrm{D}_{\mathrm{f} 13}$ can be neglected.

\section{1) IGBT turn on commutation losses}

The switching losses during the turning on interval are influenced by the rise time of the current and reverse recovery current of clamping diodes. These losses are the result of energy lost and switching frequency. Equation (17) is applied when the switch is influenced by the reverse recovery current of a diode.

$$
\begin{gathered}
P_{s w o n 12}=\frac{1}{4} f_{s w} \frac{E}{2} t_{r N} I_{C M}^{2} \int_{\alpha_{1}}^{\alpha_{2}} \sin ^{2}(t-\theta) d t \\
P_{s w o n 23}=\frac{1}{3 \pi} f_{s w} \frac{V_{d c}}{2} t_{r r N} \int_{\alpha_{1}}^{\alpha_{2}} \varepsilon\left(0.35 I_{r r N}+0.15 \frac{I_{C M} \sin (t-\theta)}{I_{C N}}\right) d t \\
+\int_{\alpha_{1}}^{\alpha_{2}} \varepsilon I_{C M} \sin (t-\theta) d t
\end{gathered}
$$

Where

$$
\varepsilon=\left(0.8+0.2 \frac{I_{C M} \sin (t-\theta)}{I_{C N}}\right)
$$

The total commutation losses during the turn-on is given by:

$$
P_{s w}=P_{s w 12}+P_{s w 23}
$$

\section{2) IGBT turn-off commutation losses}

The losses during the turn-off interval are given by:

$$
P_{o f f}=f_{S w} \frac{E}{2} I_{C M} t_{f N} \int_{\alpha_{1}}^{\alpha_{2}}\left(\frac{1}{3} \sin (t-\theta)+\frac{1}{6} \sin ^{2}(t-\theta) \frac{I_{C M}}{I_{C N}}\right) d t
$$

\section{3) Diode commutation losses}

Most of the diode commutation losses are due to the reverse conduction current, and it is given by:

$$
P_{s w D}=\frac{1}{6 \pi} f_{s w} \frac{E}{2} t_{r r N} \int_{\alpha_{1}}^{\alpha_{2}}\left(0.8+0.2 \frac{I_{C M} \sin (t-\theta)}{I_{C N}}\right) \cdot \vartheta d t
$$

where

$$
\vartheta=\left(0.35 I_{r r N}+0.15 \frac{I_{c M} \sin (t-\theta)}{I_{C N}} I_{r r N}+I_{C M} \sin (t-\theta)\right)
$$

Tabela V. Commutation intervals

\begin{tabular}{|c|c|c|c|c|}
\hline 3L-NPC & $\mathrm{S}_{11}$ & $\mathrm{D}_{\mathrm{f} 11}$ & $\mathrm{~S}_{12}$ & $\mathrm{D}_{\mathrm{c} 11}$ \\
\hline Interval & {$[\theta, \pi]$} & {$[0, \theta]$} & {$[\pi, \pi+\theta]$} & {$[\theta, \pi]$} \\
\hline
\end{tabular}




\section{Simulation Results}

A software for the proposed equations has been developed and the losses on the NPC inverter have been determined under different operating conditions.

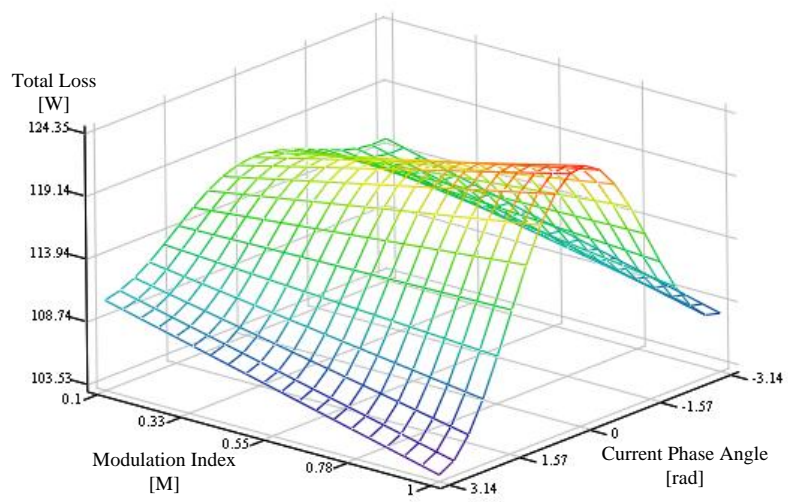

(a)

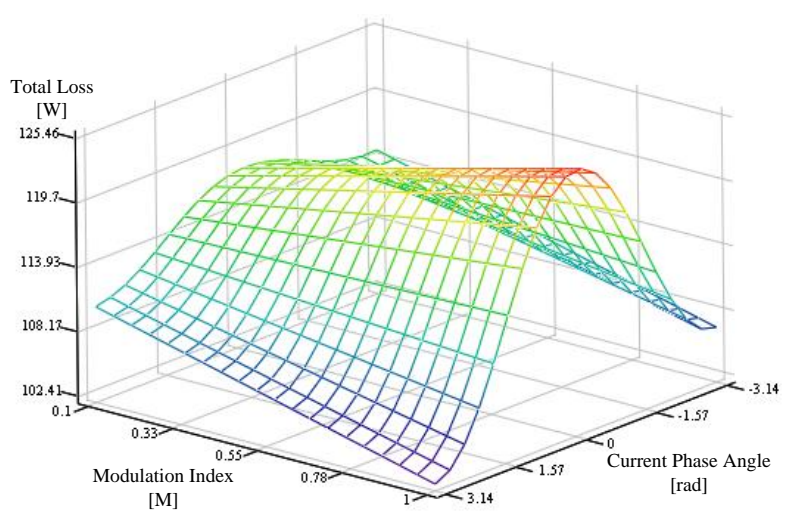

(b)

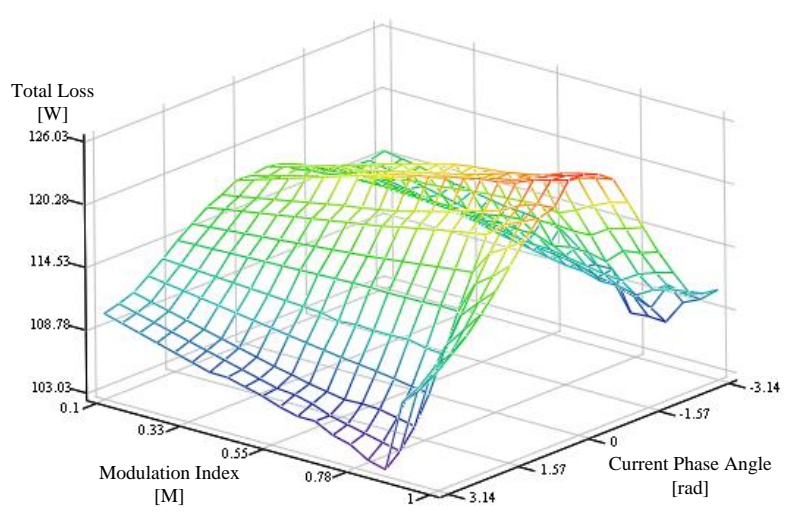

(c)

Fig. 5. Total losses for the modulations: (a) SPWM, (b) THIPWM and (c) CB-SVPWM

Figure 5 is shown the behavior of the losses as a function of the modulation index and the power factor. Analyzing the losses value provided by the studied modulations, it can be observed a similarity on the values of the estimated losses.

Figures 6 and 7 show the conduction and switching losses $\left(P_{c o n}\right.$ e $\left.P_{s w}\right)$ for a power factor $\mathrm{PF}=1$. In this condition, for a modulation index $M=0.9$ switches $S_{11}$ and $S_{12}$ are subject of the greatest voltage stress. For $M=$ 0.1 , the greatest voltage stress is across switches $S_{11}$ and $\mathrm{DC}_{11}$.

For a power factor $\mathrm{PF}=-1$, the distribution of losses is shown in Figures 8 and 9. For high modulation indices $(\mathrm{M}=0.9)$, the free-wheeling diodes are subject of the greatest voltage stress. For lower modulation index in switch $\mathrm{S}_{12}$ and clamping diode $\mathrm{DC}_{11}$ are subjected to greater voltage stress.

The conduction losses are considerably higher than the commutation losses

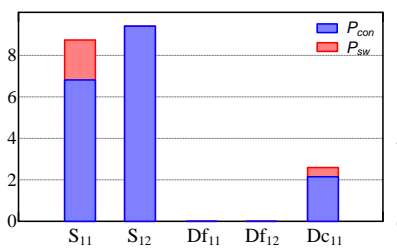

(a)

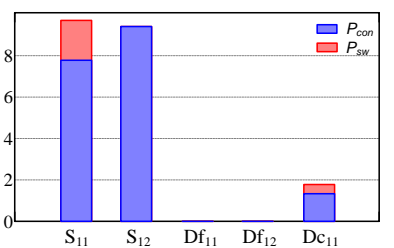

(b)

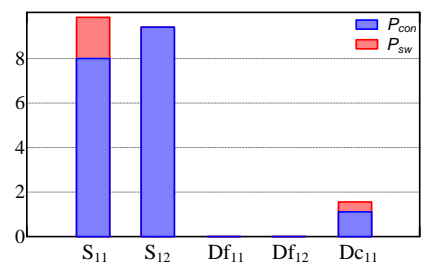

(c)

Fig. 6. Losses distribution $\left(E=500 \mathrm{~V}, I_{C M}=20, f_{s w}=2460, M=0.9\right.$, $P F=1$ ): (a) SPWM, (b) THIPWM and (c) CB-SVPWM.

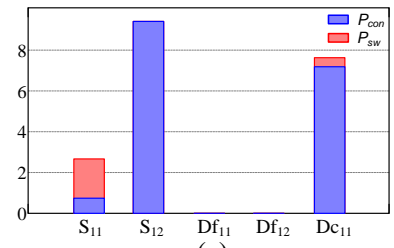

(a)

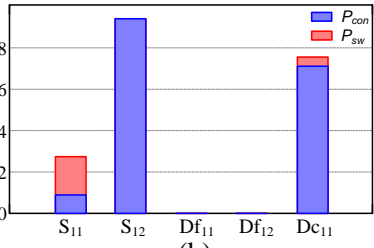

(b)

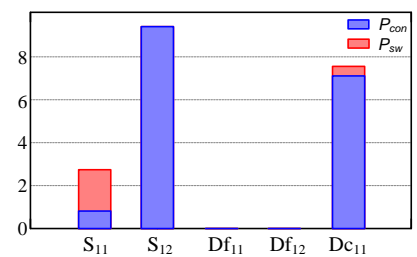

(c)

Fig. 7. Losses distribution ( $E=500 \mathrm{~V}, I_{C M}=20, f_{s w}=2460, M=0.1$, $P F=1$ ): (a) SPWM, (b) THIPWM and (c) CB-SVPWM. 


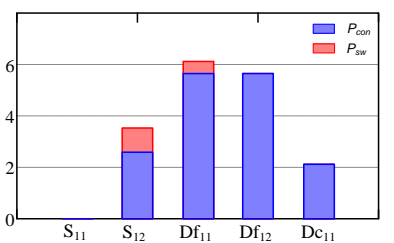

(a)

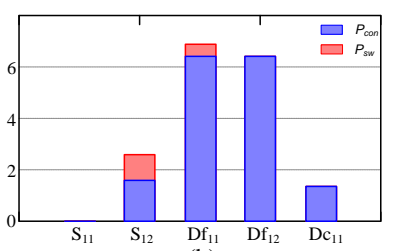

(b)

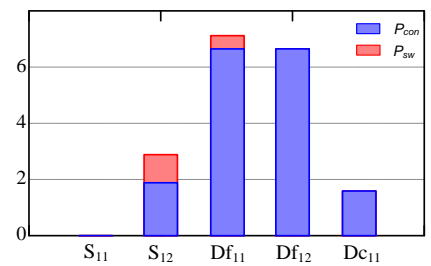

(c)

Fig. 8. Losses distribution $\left(E=500 \mathrm{~V}, I_{C M}=20, f_{S w}=2460, M=0.9\right.$, $P F=-1$ ): (a) SPWM, (b) THIPWM and (c) CB-SVPWM.

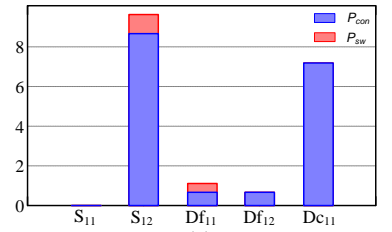

(a)

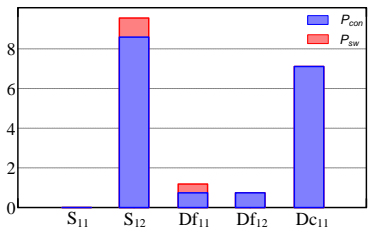

(b)

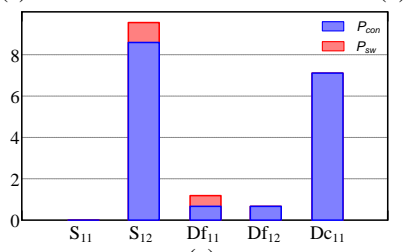

(c)

Fig. 9. Losses distibution ( $E=500 \mathrm{~V}, I_{C M}=20, f_{s w}=2460, M=0.1$, $P F=-1$ ): (a) SPWM, (b) THIPWM and (c) CB-SVPWM.

\section{Conclusion}

This paper has proposed mathematical modeling and a methodology to determine and investigate the losses distribution on a NPC inverter under different PWM modulation strategies: SPWM, THIPWM and CBSVPWM. Besides the determination of the value of the total losses, it can also be seen the imbalance in the distribution of losses. The imbalance limits the switching frequency and the rated current due to temperature rise.

\section{Acknowledgements}

Authors want to thanks $\mathrm{CNPq}$ (Brazilian Scientific Research Development Foundation) and FUNCAP (Ceara State Scientific andTechnological Development Foundation), for financially support this research.

\section{References}

[1] A. Nabae, I. Takahashi and H. Akagi, "A new neutral-pointclamped PWM inverter” IEEE Trans. Ind. Appl., Vol. IA-17, pp. 518-523, Sep./Oct. 1981.

[2] T. Brukner and S. Bernet, "Loss balancing in three-level voltage sources inverters applying active NPC swithes" PESC Conf., Vol. 2, pp. 1135-1140, 2001.

[3] A. M. Lienhardt, "Etude de la Commande et de L'Observation d'une Nouvelle Structure de Conversion d'Energie de type SMC (Convertisseur Multicellulaire Superposé)", These, Toulouse (2006).

[4] G. Buja and G. Indri, "Improvement of pulse width modulation techniques" Archiv fur Elektrotechnik, Vol. 57, pp. 281-289, 1975.

[5] D. G. Holmes, "The significance of zero space vector placement for carrier-based PWM schemes" IEEE Trans. Ind. Appl., Vol. 32, pp. 1122-1129, Sep./Oct. 1996.

[6] H. Wu and X. He, "Inherent correlation between multilevel carrier-based PWM and space vector PWM: Principle and application” IEEE PEDS'01, Vol. 1, pp. 276-281, Oct. 2001.

[7] F. Wang, "Sine-triangle versus space-vector modulation for three-level PWM voltage-source inverters" IEEE Trans. Ind. Appl., Vol. 38, pp. 500-506, Mar./Apr. 2002.

[8] N. Nho and M. Youn, "Comprehensive study on spacevector-PWM and carrier-based-PWM correlation in multilevel invertors" Proc. Inst. Elect. Eng., Vol. 153, pp. 149-158, Jan. 2006.

[9] R. Burgos et al., "Space vector modulator for vienna-type rectifiers based on the equivalence between two- and three-level converters: A carrier-based implementation" IEEE Tras. Power Electron., Vol. 23, pp. 1888-1898, Jul. 2008.

[10] F. Casanellas, "Losses in PWM inverters using IGBTs" IEE Proc. Electr. Power App., Vol. 141, pp.235-239, Sep. 1994. [11] R. P. T. Bascopé and A. J. Perin, O Transistor IGBT Aplicado em Eletrônica de Potência, Sagra Luzzatto, Porto Alegre (1997), pp. 82-94. 